\title{
Dispatch of Vehicle-to-Grid Battery Storage Using an Analytic Hierarchy Process
}

\author{
Lu Wang, Student Member, IEEE, Suleiman Sharkh, Senior Member, IEEE, Andy Chipperfield, Andrew Cruden
}

\begin{abstract}
The number of electric vehicles (EVs) is expected to increase significantly in the future to combat air pollution and reduce reliance on fossil fuels. This will impact on the power system. However, appropriate charging and discharging of EVs through vehicle-to-grid operations could also provide support for the power system and benefits for the EV owners. This raises the questions of when and how EV battery storage should be dispatched, taking into account both vehicle users' and power system's requirements and priorities, as well as the constraints of the battery system. This paper proposes a novel decentralized dispatch strategy based on the Analytic Hierarchy Process (AHP) taking into account the relative importance of the different criteria including cost, battery state of charge, power system contingency and load levelling. The proposed AHP-based dispatch strategy was tested on an IEEE Reliability Test System with different $E V$ numbers and capacities to investigate the efficacy of such an approach. The simulation results demonstrate the feasibility and benefits of this dispatch strategy.
\end{abstract}

Index Terms-Vehicle-to-grid, Battery, Dispatch, Analytic Hierarchy Process

\section{INTRODUCTION}

G ROWING concerns over energy cost and emissions and the desire to reduce reliance on fossil fuels have resulted in ambitious plans for expanding the use of electric vehicles (EVs) [1], [2], [3]. Currently the global EV market is forecast to grow from 1.7 million units in 2012 to 5.3 million units in 2020 [4]. The large-scale penetration of EVs will challenge the power system as an additional load due to the substantial need for battery charging, but it will help to increase the penetration of intermittent renewable energy sources by absorbing the extra electricity they generate [5], [6], [7]. When parked and connected to the grid, EVs are capable of feeding stored electricity back into the grid to provide grid operational support such as load levelling, spinning reserves and voltage and frequency regulation. This is the key point of the Vehicle-to-Grid (V2G) concept, which requires the EV to have a bidirectional grid-connected battery charger with metering and communication capabilities [8].

Numerous applications using battery storage to support power systems have been discussed in [9], [10], [11], [12], [13]. These functions of battery storage, including voltage and frequency control and thermal overload relief, can also be performed by EV batteries if V2G is enabled, because of

Copyright (c) 2015 IEEE. Personal use of this material is permitted. However, permission to use this material for any other purposes must be obtained from the IEEE by sending a request to pubs-permissions@ieee.org

The authors are with the Faculty of Engineering and the Environment, University of Southampton, SO17 1BJ, UK (e-mail: lw5g13@ soton.ac.uk (Lu Wang)). the significant storage/generation capacity they can offer to the grid.

Recent research has investigated and developed dispatch strategies for EV batteries when they are connected to the grid. An algorithm was proposed in [14] for optimal charging of EVs formulated as a stochastic dynamic programming problem taking into account the intrinsic uncertainty. The algorithm considers electricity procurement cost with an added inconvenience cost penalty term set by the EV owner to control the availability of the EV. However, the algorithm does not take into account investment or maintenance cost, nor does it take into account the geographical location of the vehicle and associated local network constraints.

A charging optimization approach was proposed in [15] to maximize the total electric energy that all EVs absorb from the grid while avoiding violations of the limits of voltage and components' loading, but vehicle-to-grid power flow was not considered. In [16], fuzzy logic control was used to dispatch EVs participating in the V2G scheme, so that power grid's load levelling and voltage stability were achieved. Both the state of charge of the vehicles' batteries and the voltage at the connection node were used by the controllers to determine the dispatch action. However, the cost to EV users was not considered. Lopes et al. [8] proposed a smart centralized EV charging approach to maximize the EV integration capacity of the grid. Their proposed EV grid interface control strategy allows the provision of local frequency control in an isolated system. However, the benefit for EV users were not mentioned. Risk-aware day-ahead scheduling and realtime dispatch algorithms were developed for EV charging by Yang et al. [17] to minimize the overall charging costs, but they did not consider V2G operation. An optimal charging scheduling of EV was discussed by Zhang et al. [18] to minimize the mean waiting time of EVs at a renewablepower-aided charging station under cost constraint. However, vehicle-to-grid operation was not considered. Damavandi et al. [19] proposed an energy hub model of a multi-energy system (MES) to dispatch an aggregation of EVs in parking lots in both G2V and V2G modes and considered EVs' participation in the reserve market. However, this model mainly focuses on the MES operator's benefits without considering the interests of EV owners. A collaboration of demand response strategies based on dynamic pricing and peak power limiting is investigated in [20] for home-based EV dispatch using mixed-integer linear programming (MILP), which is applied to the dayahead scheduling and the energy requirement of EV's driving activities is not considered. MILP is also used by Hua et al. 
[21] to optimize EV charging scheduling in an on-line way for both cost saving and grid stability. However, the possibility of selling energy back to the grid to increase the economic benefits was neglected in [21]. A rule-based EV battery dispatch strategy consisting of three rule sets was demonstrated by $\mathrm{Ma}$ et al. [22], where the battery characteristics, SOC and electricity buying/selling prices were considered when determining the dispatch action (i.e. charge/discharge) and the rate of dispatch (i.e. charging/discharging current), but grid operational support was not considered.

In all the literatures mentioned above, a comprehensive charging/discharging dispatch strategy for EV batteries is yet to be developed. Such a strategy needs to consider both EV users interests and grid operational requirements. Focusing on the different requirements of users and the grid will inevitably result in different dispatch patterns of EV batteries. Therefore, every requirement needs to be weighed according to its relative importance when determining the dispatch mode of EV batteries.

In this work, a novel dispatch strategy for EV batteries is developed based on the Analytic Hierarchy Process (AHP) [23]. The AHP is a multi-criteria decision-making tool that can be used to determine the priorities of different criteria (i.e. different requirements of users and grid) that can have a bearing on battery dispatch. It helps to quantify the qualitative relationship between different elements so that they can be weighed with respect to a given objective and criteria. The AHP has been applied to many decision-making related problems in power systems [24], [25], [26]. An incentive-based demand response program was proposed in [24], using the AHP to enable customers to prioritize the different criteria of load reduction that could affect their incentive payments. In [25] it was used to weigh different objective functions and the resulting weighted combination of these functions became the final objective function for combined active and reactive power dispatch. In [26] the locations of VAR sources were selected and ranked taking into account the different benefitto-cost ratios and other relevant factors, which are weighed using the AHP according to their relative importance to VAR placement.

The dispatch strategy presented in this paper takes into account the concerns and requirements of both EV users and the grid, including cost, sufficient SOC for the next journey, load levelling and alleviation of thermal overload caused by $\mathrm{N}-1$ contingency (i.e. due to maintenance or accident, one component of the transmission system consisting of $\mathrm{N}$ components is in outage, implying that the remaining $\mathrm{N}-1$ components are still working). Using the proposed strategy, the EV aggregator, in charge of a cluster of EVs, sends the dispatch command to each participating EV at the beginning of each time interval, depending on real-time data (such as real-time pricing data), situations and requirements of the EV and grid. The proposed dispatch strategy was tested on an IEEE Reliability Test System for its effectiveness at satisfying the requirements of both EV users and the grid. Comparisons with a rule-based (RB) dispatch strategy [22] are made to demonstrate the potential benefits of the proposed AHP-based dispatch strategy over previous approaches.
In summary, the contributions of this paper are as follows:

- A novel decentralized dispatch strategy using AHP is developed for V2G batteries, which takes into account multiple concerns of both EV users and the grid - see page $6-15$, Section IV.

- The proposed dispatch strategy is evaluated using historical data (see page 15-22, Section V). The simulation results show that the proposed dispatch strategy saves the EV user charging costs while ensuring at least that the SOC of the battery does not fall below 33\% (see page 19, Table IV). Meanwhile, the proposed dispatch strategy reacts to severe nearby overloads correctly and performs better in load levelling than uncontrolled dispatch and a rule-based algorithm proposed in [22] (see page 20-22, Figure 9 and 10, Table V).

- The proposed dispatch strategy is verified to be stable by running simulations on a typical system for a period of 7 consecutive days (see page 21, Figure 9).

The rest of this paper is organized as follows. The Analytic Hierarchy Process is concisely introduced in Section II, followed by a description of typical EV battery characteristics in Section III. In Section IV, the proposed dispatch strategy of EV battery storage is presented in detail. The results of simulations using MATLAB to verify its feasibility and efficacy, are presented and discussed in Section V. This is followed by a presentation and discussion of the results of parameter sensitivity analysis in Section VI. Finally, the conclusions of the work are presented in Section VII.

\section{Principles of the Analytic Hierarchy Process (AHP)}

The AHP is a multi-criteria decision-making method developed by Saaty [23], which has been widely used in various areas including power systems as mentioned earlier. The main steps of the AHP methodology can be summarized as follows:

Step 1: A hierarchy model is established based on an analysis of the problem.

Step 2: Pairwise comparison matrices $A$ are formed at each level of the hierarchy model. Each element $A(i, j)$ in the pairwise comparison matrix $A$ depicts an expert's judgement of the relative importance between the pair of $i t h$ and $j t h$ factors using the ratio scale method [23], [26] — ratio scales $\left[\frac{1}{9}, \frac{1}{8}, \frac{1}{7}, \ldots, \frac{1}{2}, 1,2, \ldots, 7,8,9\right]$ are used to demonstrate the relative importance, from overwhelmingly less important (i.e., $\frac{1}{9}$ ) to equally important (i.e., 1 ) and to overwhelmingly more important (i.e., 9), between any pair of elements. $A(i, j)$ is the reciprocal of $A(j, i)$.

Step 3: For each pairwise comparison matrix, the maximum eigenvalue and the corresponding eigenvector are calculated. The normalization of the calculated eigenvector gives the normalized principle eigenvector with elements equal to the priority scales (weightings) of the factors.

Step 4: The consistency of judgements is checked. The Consistency Index $(C I)$ and Consistency Ratio $(C R)$ are measured for each pairwise comparison matrix. The $C I$ is defined as 


$$
C I=\frac{\lambda_{\max }-n}{n-1}
$$

where $\lambda_{\max }$ and $n$ are the maximum eigenvalue and the dimension of the corresponding pairwise comparison matrix, respectively. The $C R$ is defined as

$$
C R=\frac{C I}{R I}
$$

where $R I$ is a set of given average random consistency indices which can be obtained using statistical calculations [25]. If $C R$ is no larger than $10 \%$, the inconsistency of judgements is acceptable. Otherwise, the judgements need to be revised.

In our case, in this paper, the AHP is used to determine the dispatch action based on priorities of both users and the grid; the priorities are set based on experience and common sense. The AHP is therefore subjective in nature and different users, who may or may not be experts, may have different judgements resulting in different dispatch decisions. This subjective nature and inconsistency of decision making may on the one hand be viewed as a disadvantage. But on the other hand it presents an opportunity, an advantage that allows the dispatch system to be personalised by enabling the users, whether they are aggregators, grid owners or vehicle drivers, to set their preferences and priorities.

Fuzzy logic [16] would be an interesting alternative to the AHP as it can deal with linguistic preferences and hence it may be more intuitive for some users. It is also inherently tolerant of uncertainty. But further research is needed to further evaluate efficacy and performance of fuzzy logic in this application.

Another alternative would be to use an operational research approach that searches for an optimal decision [20], [21] to say maximize profit for the aggregator while satisfying the grid and user constraints. Such an approach could have the advantage of finding a global minimum of a cost function, which is not guaranteed by the AHP. It may also be perceived to have the advantage of being more objective than the AHP. But fundamentally the decision can be skewed by the users, e.g., vehicle owners who could change their priorities and hence the constraints.

\section{BATTERY CHARACTERISTICS}

The relationship between the discharging time of a battery and the corresponding discharging current can be modelled based on the Peukert equation [27], [28], as follows:

$$
C_{p}=I^{k} T=I_{n}^{k} T_{r}=\text { constant }
$$

where $C_{p}$ is the Peukert Capacity, $k$ is the Peukert Coefficient, $I$ is the constant discharging current in Amperes and $T$ is the corresponding time the battery will last in hours. The nominal discharging current is $I_{n}$ and the rated discharging time is $T_{r}$.

Therefore, given a constant discharging current $i_{d}$ in Amperes, the corresponding available capacity $C_{a}$ of a battery in Ampere-hours (Ah) can be obtained as:

$$
C_{a}=\frac{i_{d} C_{p}}{i_{d}^{k}}=\frac{i_{d} I_{n}^{k} T_{r}}{i_{d}^{k}}
$$

The state of charge (SOC) of a battery after being discharged for $t$ hours at a constant discharging current $i_{d}$ is calculated as:

$$
S O C(t)=1-\frac{i_{d} t}{C_{a}}
$$

The characteristics of a typical EV battery is shown in Table I.

TABLE I

CHARACTERISTICS OF A TYPICAL EV BATTERY (240V, 100AH) [22]

\begin{tabular}{|c|c|c|c|c|c|}
\hline $\begin{array}{c}\text { Rated } \\
\text { Capacity } \\
(\mathrm{Ah})\end{array}$ & $\begin{array}{c}\text { Nominal } \\
\text { Current } \\
(\mathrm{A})\end{array}$ & $\begin{array}{c}\text { Nominal } \\
\text { Voltage } \\
\text { (V) }\end{array}$ & $\begin{array}{c}\text { Peukert } \\
\text { Capacity } \\
\text { (Ah) }\end{array}$ & $\begin{array}{c}\text { Charge/ } \\
\text { Discharge } \\
\text { Current } \\
(\mathrm{A})\end{array}$ & $\begin{array}{c}\text { Effective } \\
\text { Available } \\
\text { Capacity } \\
\text { (Ah) }\end{array}$ \\
\hline 100 & 20 & 240 & 182.06 & 2 & 158.5 \\
\cline { 5 - 6 } & & & & 30 & 114.87 \\
\hline
\end{tabular}

\section{Dispatch Strategy of Electric Vehicle BATTERY STORAGE}

As discussed above, by running the proposed V2G dispatch strategy for each EV, its dispatch action (i.e. whether charge or discharge and at what dispatch current) is determined by the EV aggregator (EVA) at the beginning of each time interval. In preparation for that, the aggregator gathers real-time data, such as real-time pricing data, network fixed load demand (i.e. load without EVs) and overload information, a couple of minutes prior to the beginning of each time interval. In this work, the AHP-based dispatch strategy is designed for V2G batteries to support power grid operations including load levelling and the alleviation of thermal overload caused by N-1 contingency, and to reduce cost to users while ensuring that the battery SOC is sufficient for the next journey. In order to jointly consider the different requirements of EV users and the grid, they should be weighed depending on their relative importance in determining how and when EV batteries should be dispatched and thus a hierarchy model is developed first.

\section{A. AHP Hierarchy Model}

A five-level hierarchy model for the dispatch of an EV battery is as shown in Figure 1.

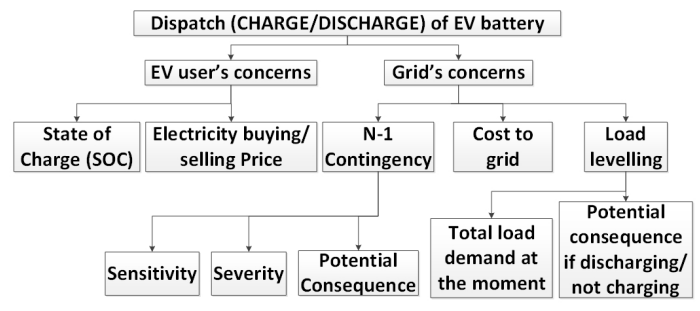

Figure 1. AHP Hierarchy Model for Dispatch of EV Battery

The top level is the objective: dispatch of the EV battery, which should take into account the requirements and concerns of both EV users and the grid (Second level criteria) as discussed earlier. EV users' main concerns are the SOC of 
the EV batteries and the cost to dispatch them (Third level sub-criteria). The grid might utilize the EVs to support system load levelling (i.e. valley filling and peak shaving) or to relieve thermal overload after an N-1 contingency while allowing for the costs of employing the storage/generation capacity of EV batteries (Third level sub-criteria). Several factors need to be considered regarding the support that an EV can provide in an $\mathrm{N}-1$ contingency such as the sensitivity of the bus to which the EV is connected in alleviating thermal overload of the overloaded lines, the severity of the overload and the potential consequence if the contingency is not dealt with in 15 minutes (Fourth level sub-criteria). Furthermore, both current system demand and potential consequence of discharging/not charging the EV battery (Fourth level sub-criteria) should be taken into account when determining the preferred support that an EV can provide for load levelling. Finally, the battery can be either charged or discharged (alternatives of dispatch actions) as a result of this decision making process.

It is important to note, as mentioned earlier, that the dispatch system is owned by the aggregator, not the EV owner. Aggregators may adjust the priorities to maximize their profit, which may change the weighting towards the grid or vice versa. Here, the concerns of EV users and the grid are considered as equally important and thus both weighed 50\%. SOC and electricity buying/selling price are also weighed equally with $50 \%$ each. Among the three sub-criteria under grid's concerns, the cost to the grid is considered to be more important than the other two (i.e. twice as important as the other two), because the power grid can choose other kinds of energy storage for grid operational support if it is more expensive to use EV batteries. The overload alleviation under N-1 contingency and load levelling are two different kinds of grid support and thus are deemed to be equally important. A pairwise comparison matrix $A_{g}$ is thus constructed as follows to derive the weightings of the three sub-criteria $(\mathrm{N}-1$ contingency $(N C)$, cost to grid $(C G)$ and load levelling $(L L))$ under grid's concerns:

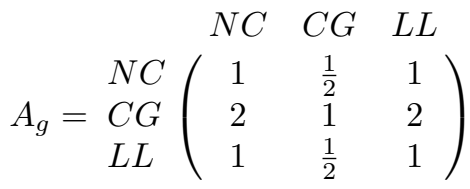

By calculating the principle eigenvector of $A_{g}$, the weightings of $N C, C G$ and $L L$, namely $w_{N C}, w_{C G}$ and $w_{L L}$, are $25 \%, 50 \%$ and $25 \%$, respectively. Among the three sub-criteria under $\mathrm{N}-1$ contingency, sensitivity is considered to be the most important, because there is no need for the EV battery to deal with the contingency that occurs far from the bus to which it is connected, no matter how severe the overload and the potential consequence. Potential consequence of the $\mathrm{N}-1$ contingency is considered to be a bit more important than severity, because a contingency that does not cause severe overload but has a severe potential consequence is surely more important and needs more attention than one that causes severe overload but no severe potential consequence. Therefore, sensitivity is determined to be 4 times as important as severity and 3 times as important as potential consequence, with potential consequence twice as important as severity. The pairwise comparison matrix $A_{N C}$ for weighing the three sub-criteria (Sensitivity (Sen), Severity $(\mathrm{Sev})$ and Potential consequence $(P o C))$ under $\mathrm{N}-1$ contingency is thus:

$$
A_{N C}=\begin{array}{ccc}
\text { Sen } & \text { Sev } & \text { PoC } \\
\operatorname{Sev} & \text { PoC }
\end{array}\left(\begin{array}{ccc}
1 & 4 & 3 \\
\frac{1}{4} & 1 & \frac{1}{2} \\
\frac{1}{3} & 2 & 1
\end{array}\right)
$$

Calculating the principal eigenvector of $A_{N C}$ gives the weightings of Sen, Sev and PoC, namely $w_{S e n}, w_{S e v}$ and $w_{P o C}$, which are $62.5 \%, 13.7 \%$ and $23.9 \%$, respectively. Moreover, the two sub-criteria under load levelling, viz. total load demand and potential consequence, are weighed $60 \%$ and $40 \%$, respectively with total load demand considered more important than potential consequence.

The factors that can be included in the AHP hierarchy model are not limited to those in Figure 1. Other factors such as battery degradation, voltage constraints and integration of renewables can be readily included. For example voltage limits, related to the distribution system for example by adding that as another grid concern in Figure 1. Indeed, additional sub-criteria specific to the distribution system can be added. But increasing the number of factors would increase complexity and implementation cost. Additionally, some factors may encompass others indirectly. For example, what an EV owner cares about most are the vehicle's basic function (i.e. driving) and the direct cost of utilizing this function (i.e. charging cost). But she or he implicitly understands (or should be told by the aggregator as part of their duty of care) that participating in a V2G will accelerate battery degradation. If he or she decides to participate in the $\mathrm{V} 2 \mathrm{G}$ scheme, then he or she would need to be convinced that the savings of charging cost, or even better getting some payment, is an adequate compensation for battery accelerated degradation. An aggregator may also offer some incentives such as paying a battery degradation charge to convince the driver that participating in $\mathrm{V} 2 \mathrm{G}$ is worth doing. In other words, the cost model includes some elements related to battery degradation. Similarly, the criteria which set a minimum and a maximum state of charge indirectly reduces the rate of battery degradation; battery life is known to improve if the depth of discharge is reduced [29], [30], for example it is well known that the cycle life of some lithiumion batteries improves from 2000 deep cycles to more than 15,000 shallow cycles (from 30\%-70\% state of charge). The driver can have the option to limit the depth of discharge (by setting the minimum and maximum SOC), to reduce battery degradation.

\section{B. Determination of the Dispatch Action}

The priorities of alternatives are determined by evaluating how suitable it is to charge/discharge the EV battery with respect to every sub-criterion as follows:

State of Charge (SOC): The upper limit of SOC $S_{\max }$ is selected to avoid overcharge, while the lower limit $S_{\min }$ is set to ensure that sufficient electric energy remains within the battery for the next journey and for the protection of the health of the battery. In V2G mode, $S_{\max }$ is set to be 0.8 and $S_{\min }=$ 
$0.4+S_{n}$ where $S_{n}$ represents the per-unit capacity that is going to be consumed on the road to the next destination. It is clear that the lower the SOC the more favourable it is to charge the battery. The higher the SOC the more favourable it is to discharge it. Therefore, the priorities of charging and discharging with respect to SOC are defined as follows:

Charge:

$$
P_{S O C}^{c}=\left\{\begin{array}{cc}
1 & S O C \leqslant S_{\min } \\
1-\frac{S O C-S_{\min }}{S_{\max }-S_{\min }} & S O C>S_{\min }
\end{array}\right.
$$

Discharge:

$$
P_{S O C}^{d}=\left\{\begin{array}{cc}
1 & S O C \geqslant S_{\max } \\
1-\frac{S_{\max }-S O C}{S_{\max }-S_{\min }} & S O C<S_{\max }
\end{array}\right.
$$

Electricity Buying/Selling Price: In order to reduce cost, it is better to charge the battery when the buying price is low and discharge it when the selling price is high. Therefore, the priorities of charging and discharging in terms of electricity price are determined as follows:

Charge:

$$
P_{E P}^{c}=\left\{\begin{array}{cl}
1 & b p \leqslant h b p \\
1-\frac{b p-h b p}{0.1 \times m b p} & b p>h b p
\end{array}\right.
$$

Discharge:

$$
P_{E P}^{d}=\left\{\begin{array}{cl}
1 & s p \geqslant h s p \\
1-\frac{h s p-s p}{0.6 \times m s p} & s p<h s p
\end{array}\right.
$$

where $b p$ and $s p$ are the electricity buying and selling prices determined by the real-time pricing information. $h b p$ and $h s p$ are the high buying and selling prices, respectively. $h b p$ is defined as $90 \%$ of the maximum buying price $m b p$, while $h s p$ is defined as $60 \%$ of the maximum selling price $m s p$ [22]. These four price values ( $h b p, h s p, m b p$ and $m s p$ ) can be determined by using the day-ahead pricing information. In this work, real pricing data recorded in [31] are used to define these four values.

$N-1$ Contingency: The priority of charging is zero with respect to an $\mathrm{N}-1$ contingency that requires discharging corrective action at the bus to which the EV is connected. Similarly, the priority of discharging is zero if the contingency requires a charging corrective action. The priorities of these actions are determined as follows:

Sensitivity: The sensitivity of load flow through a branch $b$ overloaded by an $\mathrm{N}-1$ contingency $C$ to changes of power injection at a particular bus $j$ can be evaluated using the sensitivity factor defined in [13]:

$$
S_{C}^{j}=\frac{\Delta F_{b}}{\Delta P_{j}}
$$

where $\Delta F_{b}$ is the change of power flow through the branch $b$ resulting from the change in power injection at bus $j\left(\Delta P_{j}\right)$. As certain buses have relatively higher sensitivity factors with respect to the overloaded branch than others, the same power injections at these buses could make a more obvious difference to the alleviation of the overload. Thus, an EV connected to a bus with a high sensitivity factor will have a high priority of dispatch during an N-1 contingency, while the dispatch of an EV connected to a bus with a very low sensitivity factor is not recommended due to the little contribution it can make. By comparing the sensitivity of a bus to the bus with the highest sensitivity factor, the priority of charging/discharging an EV at a specific bus with respect to sensitivity $P_{\text {sen }}$ can be defined as:

$$
P_{\text {sen }}=\frac{\left|S_{C}^{j}\right|}{\max \left\{\left|S_{C}^{1}\right|,\left|S_{C}^{2}\right| \ldots\left|S_{C}^{n b}\right|\right\}}
$$

where $n b$ is the total number of buses in the system.

Severity: The severity of overload can be quantified as a percentage of the Long Term Emergency (LTE) rating of the overloaded line, as follows:

$$
\text { Severity }=\frac{\text { Load Flow }- \text { LTE }}{L T E} \times 100 \%,
$$

where LTE rating can be derived from [32], while Load Flow is obtained by carrying out the power flow analysis for the network under an $\mathrm{N}-1$ contingency. The priority of charging/discharging with respect to overloading severity $P_{\text {sev }}$ is determined as:

$$
P_{\text {sev }}=\frac{S e v_{C}}{S e v_{\max }}
$$

where $S e v_{C}$ is the severity of overloading caused by contingency $C$ and $S e v_{\max }$ is the severity of the severest overload caused by the severest contingency, which is derived by running the simulation of power flow analysis for all possible $\mathrm{N}-1$ contingencies within the network, calculating the severity of overload they caused using (14) and then selecting the maximum.

Potential Consequence: Potential consequence of an $\mathrm{N}-1$ contingency is determined by the number of overloaded lines, assuming that the branch overloaded by the contingency is broken due to the absence of an in-time measure. The priority of charging/discharging in terms of potential consequence $P_{P o C}$ is calculated as follows:

$$
P_{P o C}=\frac{\operatorname{Poc}_{C}}{P_{\text {oc }} \text { max }}
$$

where $\mathrm{Poc}_{C}$ is the potential consequence of contingency $C$ and $P o c_{\max }$ is the severest potential consequence.

Cost to Grid: When charging the EV battery, the cost to the grid is $C_{c}$. However, when discharging it, the cost is $C_{d}$. From the grid's perspective, the lower the cost the better. Therefore, the priorities of charging and discharging in terms of the cost to grid are evaluated as follows:

Charge:

$$
P_{C G}^{c}= \begin{cases}1 & C_{c} \leqslant H C C \\ 0 & C_{c}>H C C\end{cases}
$$

Discharge:

$$
P_{C G}^{d}=\left\{\begin{array}{cc}
1 & C_{d} \leqslant L D C \\
\frac{H D C-C_{d}}{H D C-L D C} & L D C<C_{d}<H D C \\
0 & C_{d} \geqslant H D C
\end{array}\right.
$$

where $H C C$ is the high cost to the grid for charging an EV and is set to be zero in this paper because the cost to the grid to charge an EV is negative and the cost to discharge an EV 
is positive in this paper. $H D C$ and $L D C$ are respectively the high and low costs to grid for discharging an EV and are set to be $£ 0.02 / \mathrm{KWh}$ and $£ 0.01 / \mathrm{KWh}$ respectively in this paper [31].

\section{Load Levelling:}

Total Load Demand: In order for load levelling (i.e. peak shaving and valley filling) to be effective, it is better for EVs to be charged when the network's original load demand (i.e. the system load without EV integration) is low, so that EVs can store energy for the driving activities and grid operational support that might happen afterwards, while discharged to provide energy to the grid when the network's original load demand is high. Therefore, the priorities of charging and discharging in this case are defined as:

Charge:

$$
P_{L D}^{c}=\left\{\begin{array}{cc}
1 & d \leqslant L D \\
1-\frac{d-L D}{0.25\left(d_{\max }-d_{\min }\right)} & L D<d<M D \\
0 & d \geqslant M D
\end{array}\right.
$$

Discharge:

$$
P_{L D}^{d}=\left\{\begin{array}{cc}
1 & d \geqslant H D \\
1-\frac{H D-d}{0.25\left(d_{\max }-d_{\min }\right)} & M D<d<H D \\
0 & d \leqslant M D
\end{array}\right.
$$

where $d_{\max }$ and $d_{\min }$ are the maximum and minimum system demand during a day which can be determined using dayahead load forecasting data or the historical data. In this work, real load demand data [31] are used to define these two values. $M D$ is the mid-level system demand, calculated as

$$
M D=0.5 \times\left(d_{\max }+d_{\min }\right)
$$

$L D$ is the low-level system demand, determined by

$$
L D=d_{\min }+0.25 \times\left(d_{\max }-d_{\min }\right)
$$

$H D$ is the high-level system demand, determined by

$$
H D=d_{\max }-0.25 \times\left(d_{\max }-d_{\min }\right)
$$

Potential Consequence: The potential consequence if discharging/not charging the battery is evaluated based on its SOC. If the EV battery is discharged/not charged at a given time, there might not be enough electric energy within the battery to be discharged during high load periods. Therefore, the priorities of charging and discharging are determined as follows:

Charge:

$$
P_{L P o C}^{c}=\left\{\begin{array}{cc}
1 & S O C \leqslant S g_{\min } \\
1-\frac{S O C-S g_{\min }}{S g_{\max }-S g_{\min }} & S O C>S g_{\min }
\end{array}\right.
$$

Discharge:

$$
P_{L P o C}^{d}=\left\{\begin{array}{cc}
1 & S O C \geqslant S g_{\max } \\
1-\frac{S g_{\max }-S O C}{S g_{\max }-S g_{\min }} & S O C<S g_{\max }
\end{array}\right.
$$

where $S g_{\min }$ and $S g_{\max }$ are low and high SOC from the perspective of grid and selected to be 0.4 and 0.8 , respectively, for the normal operation of EV batteries.
The final priorities $P_{f}$ of charging and discharging an EV are calculated in the same way, that is:

$$
\begin{aligned}
P_{f}= & \left(P_{S O C} \times w_{S O C}+P_{E P} \times w_{E P}\right) \times w_{E V} \\
& +\left(\left(P_{s e n} \times w_{s e n}+P_{\text {sev }} \times w_{\text {sev }}+P_{P o C}\right.\right. \\
& \left.\times w_{P o C}\right) \times w_{N C}+P_{C G} \times w_{C G}+\left(P_{L D}\right. \\
& \left.\left.\times w_{L D}+P_{L P o C} \times w_{L P o C}\right) \times w_{L L}\right) \times w_{G}
\end{aligned}
$$

where $P_{S O C}, P_{E P}, P_{s e n}, P_{s e v}, P_{P o C}, P_{C G}, P_{L D}, P_{L P o C}$ are the priorities of charge/discharge with respect to SOC, electricity price, sensitivity, severity, potential consequence of $\mathrm{N}-1$ contingency, cost to grid, total load demand and potential consequence of load levelling, respectively. $w_{S O C}, w_{E P}$, $w_{\text {sen }}, w_{\text {sev }}, w_{P o C}, w_{C G}, w_{L D}, w_{L P o C}$ are the corresponding weighting factors. $w_{N C}$ and $w_{L L}$ are the weightings of $\mathrm{N}-1$ contingency and load levelling with respect to grid's concerns. $w_{E V}$ and $w_{G}$ are respectively the weightings of EV users' and grid's concerns in terms of the objective.

The above forms the main part of the decision making process for the dispatch of an EV's battery. It is important to note that the information about the next journey $S_{n}$ is assumed to be available. The SOC of an EV battery is checked at the beginning of each time interval. If the SOC is less than $S_{m i n}$, the battery is charged during the current time interval. Otherwise, if the SOC is larger than $S_{\max }$, it is discharged. The dispatch action is determined as the one that has the highest final priority if the SOC is between $S_{\min }$ and $S_{\max }$. How fast the battery is charged/discharged depends on the final priority $P_{f}$ of charge/discharge. If $P_{f}$ is no less than 0.9 , the EV is charged/discharged at the high current level set here to be 30A. If $P_{f}$ is between 0.7 and 0.9 , the EV is charged/discharged at the middle-level current of $10 \mathrm{~A}$. If $P_{f}$ is between 0.4 and 0.7 , the EV is charged/discharged at a low-level current of $2 \mathrm{~A}$. Otherwise, when $P_{f}$ is lower than 0.4 , the EV battery is idle during this time interval. The overall AHP-based dispatch strategy is shown in Figure 2, which is implemented at the beginning of each time interval for each $\mathrm{EV}$ by the EV aggregator using the real-time data gathered a couple of minutes beforehand. The detailed data communication chart is illustrated in Figure 3, which describes the procedure of real-time data collection from EVs and system operators, the working process of the aggregator and the transmission of dispatch action commands to EVs. The aggregator collects data from the EVs, DSO and TSO and sends dispatch commands to the EVs. For comparison, the flow chart of the rule-based dispatch strategy described in [22] is given in Figure 4. The key parameters of the two dispatch strategies are set to be the same for the fair comparison, as shown in Table II.

\section{Simulation Test}

The proposed AHP-based dispatch strategy was tested on an IEEE Reliability Test System (RTS) [32], which is formed of 24 buses and 38 branches as shown in Figure 5, and implemented using MATLAB and MATPOWER 4.1 [33]. The reason why RTS is used for simulation test is because this paper mainly focuses on the application of V2G in the 


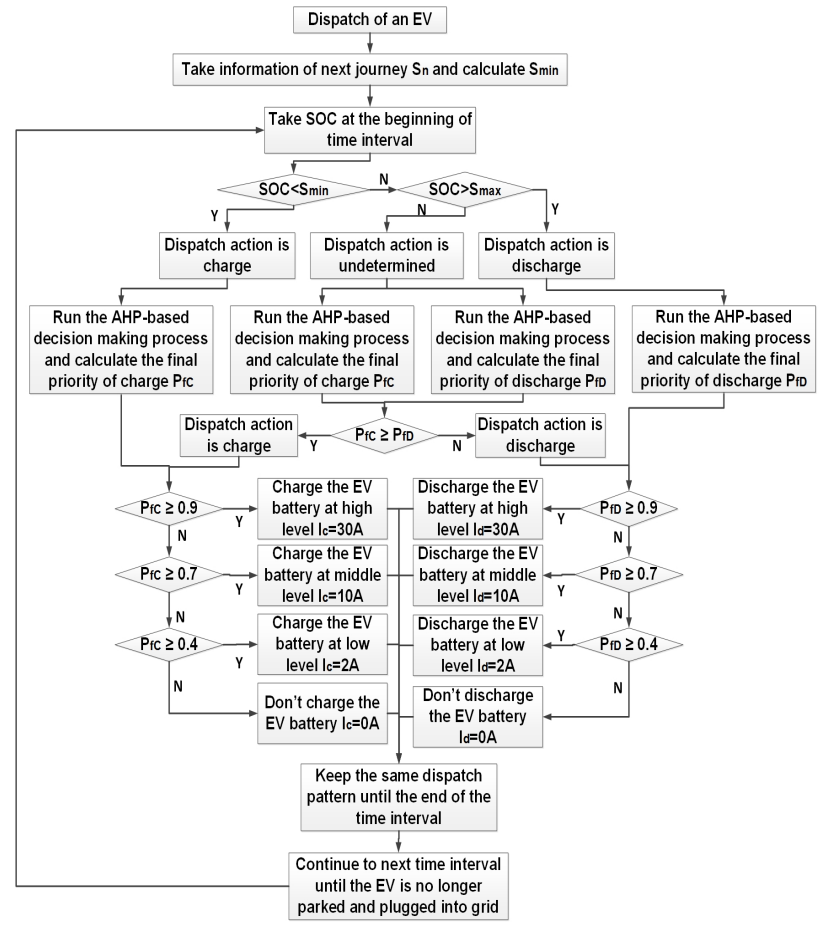

Figure 2. AHP-based Dispatch Strategy for an EV Battery

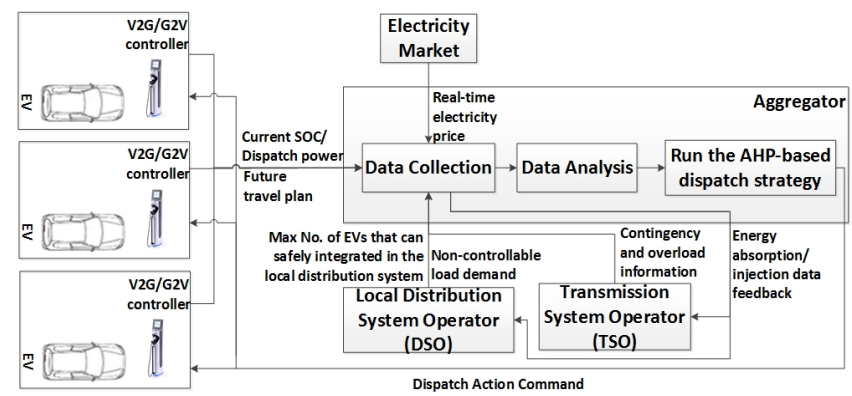

Figure 3. Data Communication Chart

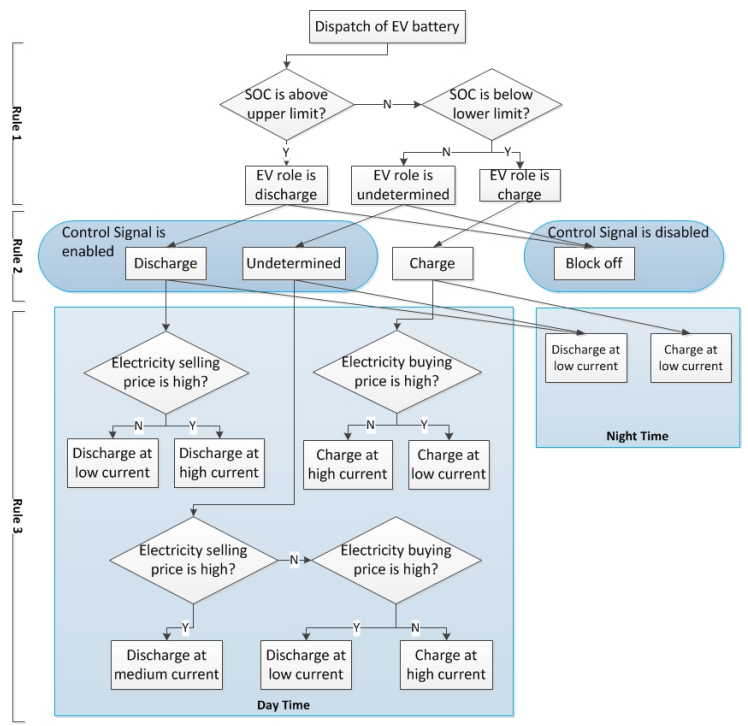

Figure 4. Rule-based Dispatch Strategy for an EV Battery [22]
TABLE II

Key Parameter Settings for AHP-BASEd AND RUle-BASED DISPATCH STRATEGIES

\begin{tabular}{|c|c|c|c|c|}
\hline $\begin{array}{c}\text { Dispatch } \\
\text { Strategy }\end{array}$ & $S O C_{\min }$ & $S O C_{\max }$ & $\begin{array}{c}\text { High Buying } \\
\text { Price } h b p \\
(£ / \mathrm{KWh})\end{array}$ & $\begin{array}{c}\text { High Selling } \\
\text { Price } h s p \\
(£ / \mathrm{KWh})\end{array}$ \\
\hline $\begin{array}{c}\text { AHP- } \\
\text { based }\end{array}$ & 0.4 & 0.8 & 0.15 & 0.11 \\
\hline $\begin{array}{c}\text { Rule- } \\
\text { based }\end{array}$ & 0.4 & 0.8 & 0.15 & 0.11 \\
\hline \hline $\begin{array}{c}\text { Dispatch } \\
\text { Strategy }\end{array}$ & $\begin{array}{c}\text { High } \\
\text { Dispatch } \\
\text { Current }\end{array}$ & $\begin{array}{c}\text { Medium } \\
\text { Dispatch } \\
\text { Current }\end{array}$ & $\begin{array}{c}\text { Low } \\
\text { Dispatch } \\
\text { Current }\end{array}$ & $\begin{array}{c}\text { On-road } \\
\text { Discharging } \\
\text { Current }\end{array}$ \\
\hline $\begin{array}{c}\text { AHP- } \\
\text { based }\end{array}$ & 30 & 10 & 2 & 20 \\
\hline $\begin{array}{c}\text { Rule- } \\
\text { based }\end{array}$ & 30 & 10 & 2 & 20 \\
\hline
\end{tabular}

transmission system in terms of load levelling and overload alleviation under $\mathrm{N}-1$ contingency. The EVs that are distributed within the local distribution network are aggregated and connected at a bus of transmission system that this local network is connected to, under the assumption that the integration of EVs will not overload the local distribution network.

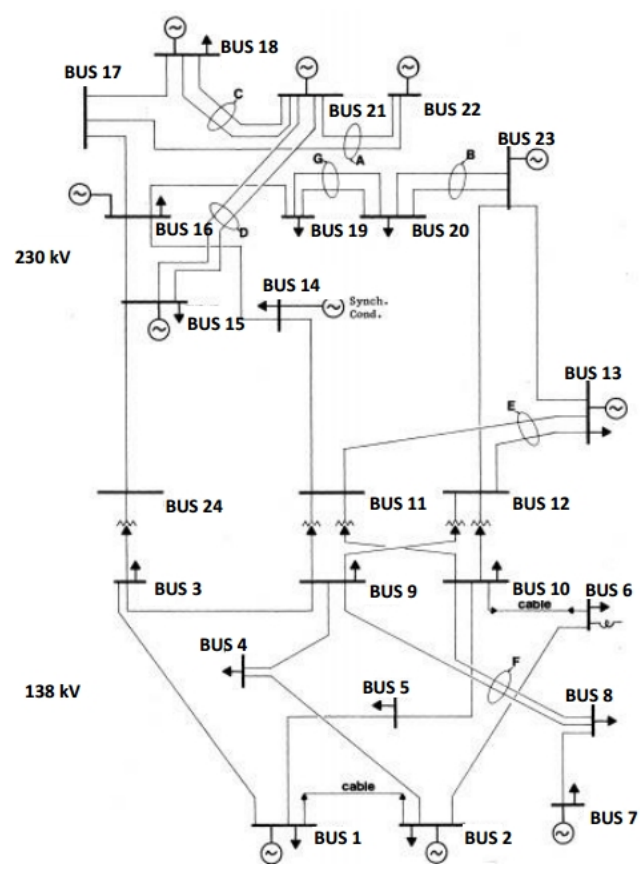

Figure 5. Diagram of IEEE Reliability Test System [32]

The total load demand and system selling/buying price of electricity during a day was taken from [31]. The total load demand is scaled down so that the peak demand during a day is $3300 \mathrm{MW}$, which approximately represents the daily load demand in a large UK city, as shown in Figure 6. Due to a scarcity of information on the payments by/to EV users when the EVs are charged/discharged, the system selling/buying price [31], is adjusted based on domestic tariffs using the method proposed in [22] to represent EV users' selling/buying 


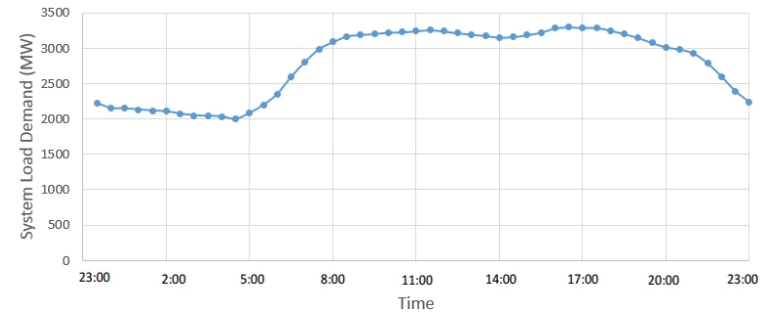

Figure 6. Total Load Demand During A Day without EV Load

price of electricity. The adjusted system selling/buying price is derived by adding the difference between the average tariff value and the average system selling/buying price to the corresponding system selling/buying price, as shown in Figure 7. The average ASSP and average ASBP become the same and equal to the average of domestic tariff, therefore ASBP can be either higher or lower than ASSP. Therefore, the ASSP (i.e. adjusted system selling price) and ASBP (i.e. adjusted system buying price) in Figure 7 are used as the EV charging and discharging prices respectively, namely the $b p$ in (10) and $s p$ in (11) respectively. $C_{c}$ in (17) is defined as the difference between system buying price and system selling price in Figure 7, namely $C_{c}=S S P-S B P . C_{d}$ in (18) is set to be the difference between EV discharging price and charging price, that is, $C_{d}=A S B P-A S S P$. The time step is set to be 30 minutes. The dispatch actions are determined by the dispatch strategy at the beginning of every time interval and lasts for the entire time interval of 30 minutes.

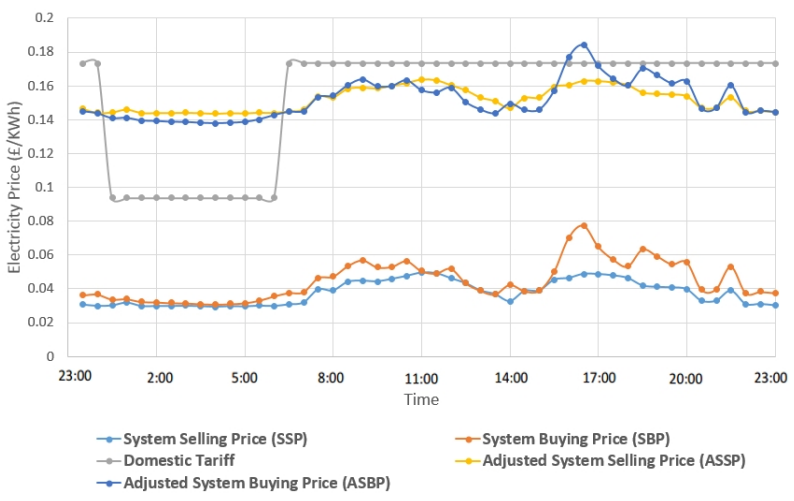

Figure 7. Daily Electricity Price

To test the AHP-based dispatch strategy, an EV is connected to bus 6 when it is parked and plugged into the grid. When the EV is on the road, the battery electric energy is assumed to be consumed at the nominal discharging current (20A) as assumed in [22]. The EV's travel pattern and electric capacity requirements for the next journey, $S_{n}$, during a day are described in Table III. It is important to note that the travel pattern used here was randomly generated and utilized as an example. The EV can have any kind of travel pattern, which will not affect the feasibility of the proposed dispatch strategy. The simulation results of the EV's SOC and net cost to EV users (i.e. charging cost-discharging payment) during a day are shown in Table IV, compared with those generated by applying the rule-based dispatch strategy that has been developed in
[22].

TABLE III

EV's TRAVEL PATTERN AND $S_{n}$ DURING A DAY

\begin{tabular}{|c|c|c|}
\hline Time & Travel Pattern & $S_{n}$ \\
\hline 23:00-7:00 & Parked & 0.2 \\
\hline 7:00-8:00 & on road & n/a \\
\hline 8:00-12:00 & Parked & 0.1 \\
\hline 12:00-12:30 & on road & n/a \\
\hline 12:30-13:30 & Parked & 0.1 \\
\hline 13:30-14:00 & on road & n/a \\
\hline 14:00-18:00 & Parked & 0.2 \\
\hline 18:00-19:00 & on road & $\mathrm{n} / \mathrm{a}$ \\
\hline 19:00-23:00 & Parked & 0.2 \\
\hline
\end{tabular}

TABLE IV

SOC AND DAILY COST OF AN EV - COMPARISONS BETWEEN THE PROPOSED AHP-BASED DISPATCH STRATEGY AND THE RULE-BASED STRATEGY

\begin{tabular}{|c|c|c|c|}
\hline $\begin{array}{c}\text { Dispatch } \\
\text { Strategy }\end{array}$ & $\begin{array}{c}\text { Lowest } \\
\text { SOC }\end{array}$ & $\begin{array}{c}\text { Highest } \\
\text { SOC }\end{array}$ & $\begin{array}{c}\text { Costs } \\
(£)\end{array}$ \\
\hline $\begin{array}{c}\text { AHP- } \\
\text { based }\end{array}$ & 0.331 & 0.694 & 2.25 \\
\hline $\begin{array}{c}\text { Rule- } \\
\text { based }\end{array}$ & 0.194 & 0.657 & 1.39 \\
\hline
\end{tabular}

In Table IV, it is shown that under the same travel pattern the AHP-based dispatch strategy results in better SOC conditions of the EV though costing $£ 0.86$ more per day than the rulebased strategy. The improved SOC condition produced by the AHP-based dispatch strategy with the SOC remaining in the main within the desired range [0.4, 0.8]. The lowest $\mathrm{SOC}$ is just below 0.4 , which implies a more reliable driving experience, compared to the lowest SOC of 0.194 when using rule-based strategy. This could justify the higher daily cost of the AHP-based strategy. Furthermore, if the EV battery, without V2G service, is quickly fully charged after every use (i.e. using $30 \mathrm{~A}$ charging current) to recover the electricity consumed on the road, the daily cost per vehicle will be $\$ 3.08$ under the same travel pattern as shown in Table III, which demonstrates the capability of AHP-based dispatch strategy to save costs while ensuring sufficient SOC in the battery for reliable driving.

As for the effectiveness of the AHP-based dispatch strategy in dealing with an $\mathrm{N}-1$ contingency, the EV battery dispatch action can be affected by the occurrence of a severe N-1 contingency and the overloading it causes can be efficiently relieved by power injection/absorption at the bus to which the EV is connected. The simulation results using the AHP-based dispatch strategy show that a car's battery is charged at $479 \mathrm{~W}$ from 9:00 am to 9:30 am if no contingency occurred. However, if branch 10 is broken (N-1 contingency) at 9 am, which results in the overloading of branch 5 , power injection will 
be required at bus 6 meaning that the connected EV battery is preferably discharged. By applying the AHP-based dispatch strategy, the EV is set to be discharged at $479 \mathrm{~W}$. The rulebased dispatch strategy that was proposed in [22] does not take N-1 contingency into account and thus makes the same decision on the dispatch action of the EV battery regardless of the contingency - using this strategy an EV battery will in fact be charged at $468 \mathrm{~W}$ at 9:00 am, which will aggravate the overloading caused by the outage of branch 10 .

The highest charging/discharging power of an EV is 7731 $\mathrm{W}$, which is negligible compared to the total load demand of the system. Therefore, in order to test the efficacy of the proposed AHP-based dispatch strategy on load levelling, a total number of $625000 \mathrm{EVs}$ are assumed to be in the system. This is a predicted number of EVs in a large UK city after 2035 (EVs are predicted to comprise $25 \%$ of the total car population after 2035, and there are about 2.5 million cars in a large UK city). These EVs are randomly allocated in the system while power flow analysis is used to make sure that no overload occurs. The initial SOC of EVs are randomly assigned with a normal probability distribution $(\mu=0.6, \sigma=0.1)$. A probability curve, illustrated in Figure 8, is used to determine the total number of parked EVs at each time interval. But EVs that leave or arrive at the parking lot are randomly selected. Therefore, for each EV, the departure and arrival times are totally stochastic.

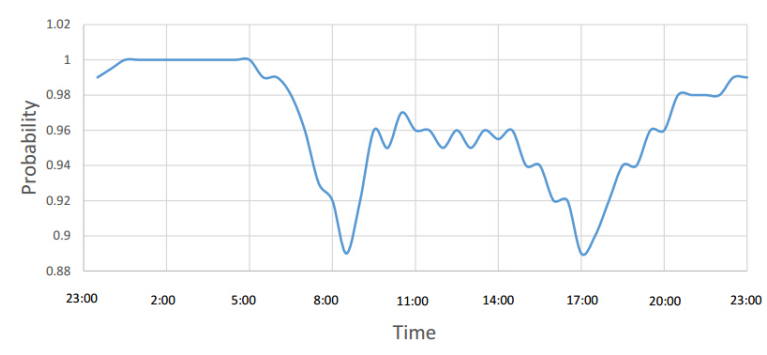

Figure 8. Probability of cars that are parked during a weekday [22]

In order to measure the total load demand and system transmission loss, the power injected at the slack bus of the test system (bus 13) is evaluated for all the cases including the cases where EVs are charged in an uncontrolled fashion (i.e. EVs are fast charged at a high current level (30A) after each journey) and where EVs are dispatched by the AHPbased strategy and the rule-based strategy. The power injection at the slack bus represents the power exchange between the power system under investigation and the rest of the grid. Simulation results for the power injections at the slack bus during 7 days are presented in Figure 9. The choppy transient response during the first day is due to the random assignment of the SOC of the EVs at the start of the simulation. The following days start with the SOC of EV batteries that have settled to a steady state value, hence the repeatable steady pattern of the power injected at the slack bus during the rest of the days, which confirms the stability of the dispatch strategies. Figure 10 shows power injections into the slack bus during the seventh day with the original curve of power injected at the slack bus when the grid is operated without EVs. Certain key data in Figure 10 is given in Table V.

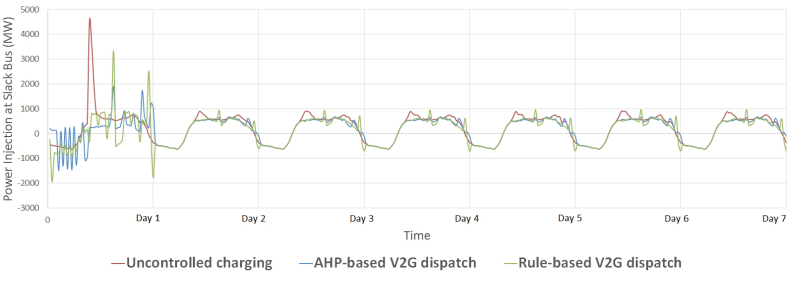

Figure 9. Power injections at the slack bus for all three cases during a week

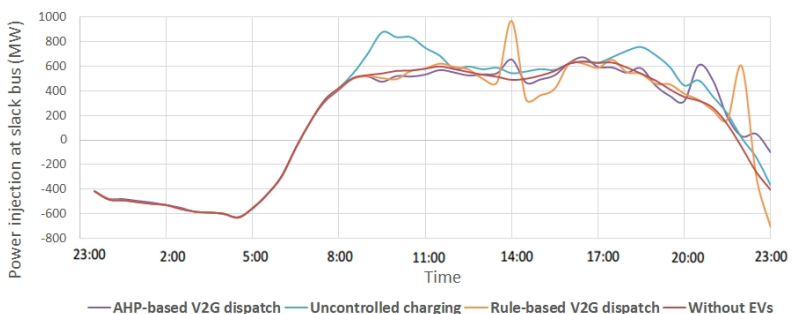

Figure 10. Power injections at the slack bus for all three cases during a day

TABLE V

NUMERICAL ANALYSIS OF THE EFFICACY OF AHP-BASED DISPATCH STRATEGY IN LOAD LEVELLING COMPARED WITH THAT OF RULE-BASED DISPATCH STRATEGY AND UNCONTROLLED CHARGING

\begin{tabular}{|c|c|c|}
\hline Dispatch Strategy & $\begin{array}{c}\text { Lowest Power Injection } \\
\text { (MW) }\end{array}$ & $\begin{array}{c}\text { Highest Power Injection } \\
\text { (MW) }\end{array}$ \\
\hline AHP-based & -626.3 & 673.4 \\
\hline Rule-based & -706.5 & 969.5 \\
\hline Uncontrolled & -630.5 & 877.5 \\
\hline
\end{tabular}

As shown in Table $\mathrm{V}$, the rule-based dispatch strategy and uncontrolled charging result in very high peaks of power injections, which are respectively about 200 and 300 MW higher than the peak power injection when using AHP-based strategy. Therefore, AHP-based dispatch strategy has better performance in peak shaving compared to the two other strategies in the sense of creating much lower peak power injection from the main grid. During the off-peak period, the AHP-based dispatch strategy results in at most $626.3 \mathrm{MW}$ power to be transferred to the main grid, while uncontrolled charging results in about $4 \mathrm{MW}$ more power being absorbed by the main grid. The rule-based strategy results in $80 \mathrm{MW}$ more power being injected into the main grid. Thus, AHPbased strategy performs better in valley filling than rule-based strategy and uncontrolled charging.

\section{SEnsitivity AnALYsis}

In order to further investigate and understand the characteristics of the proposed AHP-based dispatch strategy, sensitivity analysis is carried out for many different scenarios. First of all, the effects of changing the weightings of EV users' and grid's concerns (i.e. $w_{E V}$ and $w_{G}$ respectively) on the EV daily SOC and cost are investigated, as well as the impacts of the relative importance between SOC $w_{S O C}$ and electricity price $w_{E P}$.

As shown in Table VI, when the weighting of EV users' concerns $w_{E V}$ increases, more attentions are paid to the EV user's benefits, hence the daily SOC condition of EV improves, as illustrated in Figure 11 (the corresponding current levels and 
final priorities of dispatch decisions are presented in Figure 12 and Figure 13, respectively), normally leading to an increasing charging cost. That is not hard to understand, because a better SOC condition implies more electric energy to be charged or less to be discharged, which increases the daily cost to EV users. However, when the EV's SOC condition is already good enough within the $40 \%$ and $80 \%$, the increase of $w_{E V}$ does not improve the daily SOC condition of the EV but reduces the daily cost for the EV (e.g. when $w_{S O C}=80 \%$, $w_{E P}=20 \%$ with $w_{E V}=50 \%$ and $80 \%$ respectively, as can be seen in Figure 11). That is because when the EV's daily SOC condition is already good enough, due to having a high priority, the improvement space becomes very limited. Thus, increasing $w_{E V}$ to continually increase its composite priority will not make significant improvement to the SOC condition. But, the increase of the composite priority of cost due to increasing $w_{E V}$ will tend to charge the EV at the low buying price instead of scattering the charging process over a wide period to avoid increasing the peak load demand. Moreover, when keeping the weightings of EV user and grid concerns unchanged but adjusting the relative importance between the two criteria, SOC and electricity price, the results change as well, as demonstrated in Figure 14 (the corresponding current levels and final priorities of dispatch decisions are presented in Figure 15 and Figure 16, respectively). With a higher weighting given to electricity price (i.e. $w_{E P}$ is higher but $w_{S O C}$ is lower), it will be better to discharge an EV battery due to the high selling price, in order to save costs, than to charge it due to the low SOC. Thus, discharging might be chosen as the current dispatch action and the daily cost to the EV user, unsurprisingly, decreases as SOC condition worsens. However, with higher $w_{S O C}$ but lower $w_{E P}$, the dispatch action recommended for ensuring that sufficient electricity remains in the battery will have a higher priority to be chosen as the current EV dispatch action than that recommended according to electricity price to save cost. The SOC condition is therefore, as expected, better with increasing daily cost.

TABLE VI

SENSITIVITY ANALYSIS: THE EFFECTS OF CHANGING THE WEIGHTINGS OF CRITERIA ON THE EV DAILY SOC AND COST

\begin{tabular}{|c|c|c|c|c|c|c|}
\hline \multirow{2}{*}{$\frac{w_{E V}}{w_{G}}$} & \multicolumn{2}{|c|}{$\begin{array}{c}w_{S O C}=20 \% \\
w_{E P}=80 \%\end{array}$} & \multicolumn{2}{|c|}{$\begin{array}{c}w_{S O C}=50 \% \\
w_{E P}=50 \%\end{array}$} & \multicolumn{2}{|c|}{$\begin{array}{c}w_{S O C}=80 \% \\
w_{E P}=20 \%\end{array}$} \\
\hline & $S O C$ & $\begin{array}{c}\text { Cost } \\
(£)\end{array}$ & $S O C$ & $\begin{array}{c}\text { Cost } \\
(£)\end{array}$ & $S O C$ & $\begin{array}{l}\text { Cost } \\
(£)\end{array}$ \\
\hline$\frac{20 \%}{80 \%}$ & $\begin{array}{l}{[0.16,} \\
0.69]\end{array}$ & 0.66 & $\begin{array}{l}{[0.18,} \\
0.69]\end{array}$ & 0.82 & $\begin{array}{l}{[0.19,} \\
0.69]\end{array}$ & 0.89 \\
\hline$\frac{50 \%}{50 \%}$ & $\begin{array}{l}{[0.19,} \\
0.70]\end{array}$ & 1.59 & $\begin{array}{l}{[0.33,} \\
0.69]\end{array}$ & 2.25 & $\begin{array}{l}{[0.47,} \\
0.70]\end{array}$ & 2.62 \\
\hline$\frac{80 \%}{20 \%}$ & $\begin{array}{l}{[0.28,} \\
0.75]\end{array}$ & 1.87 & $\begin{array}{l}{[0.36,} \\
0.71]\end{array}$ & 2.35 & $\begin{array}{l}{[0.47,} \\
0.70]\end{array}$ & 2.44 \\
\hline
\end{tabular}

As for the impact of different settings of $w_{G}$ and $w_{E V}$ on the network, similar sensitivity analysis is carried out and the result is shown in Figure 17. The corresponding accumulated energy injections are presented in Table VII. It is clear in Figure 17 that the network load demand curve is improved, in terms of decreasing peak load demand, with higher weighting assigned to grid's concerns, which is just as expected and easy to understand. It is evident from Table VII

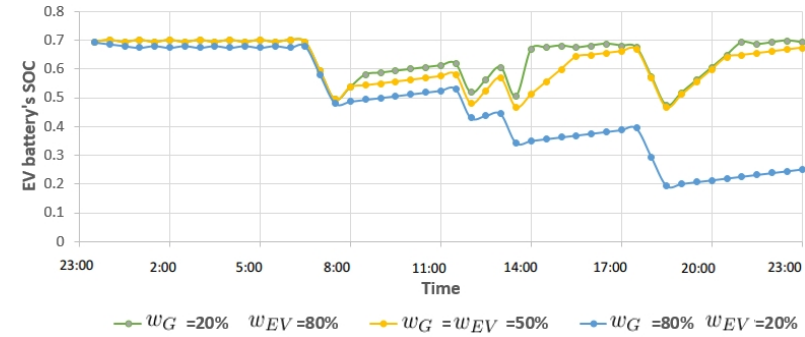

Figure 11. Daily SOC conditions of an EV battery under different settings of $w_{G}$ and $w_{E V}$ but constant $w_{S O C}(80 \%)$ and $w_{E P}(20 \%)$

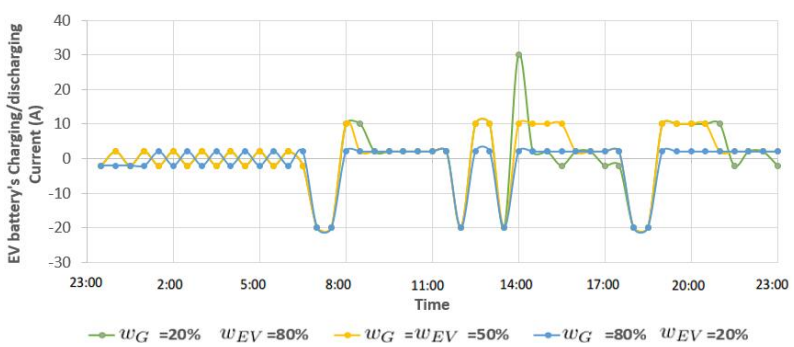

Figure 12. Charging/discharging currents of an EV battery under different settings of $w_{G}$ and $w_{E V}$ but constant $w_{S O C}(80 \%)$ and $w_{E P}(20 \%)$

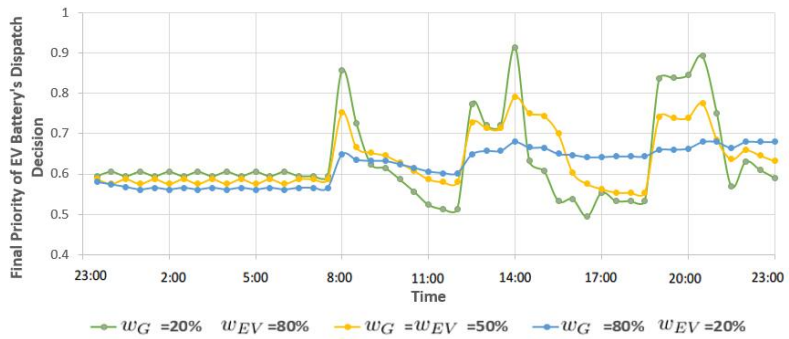

Figure 13. Final priorities of dispatch decisions of an EV battery under different settings of $w_{G}$ and $w_{E V}$ but constant $w_{S O C}(80 \%)$ and $w_{E P}$ $(20 \%)$, which decide the dispatch current levels in Figure 12 and hence SOC conditions in Figure 11

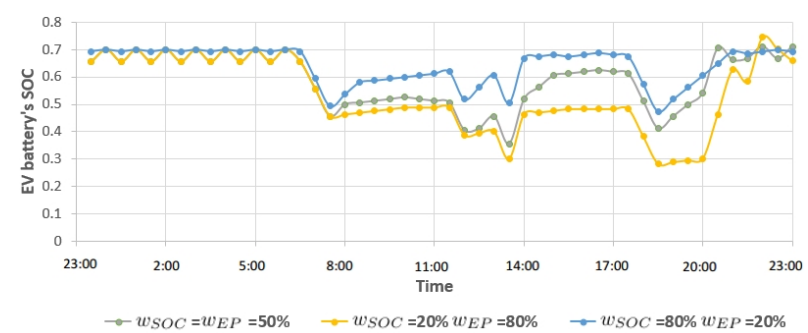

Figure 14. Daily SOC conditions of an EV battery under different settings of $w_{S O C}$ and $w_{E P}$ but constant $w_{G}(20 \%)$ and $w_{E V}(80 \%)$

that when the weighting of grid concerns $\left(w_{G}\right)$ becomes high at $80 \%$ the amount of energy injected at the slack bus reduces significantly. This is expected as load levelling takes priority as can be seen in Figure 17.

As mentioned earlier, the setting of weightings of the AHP model is based mainly on expert experience and common sense. In practice we envisage that the initial weighting determined based on common sense will be refined based on simulation results at the design stage or over time during 


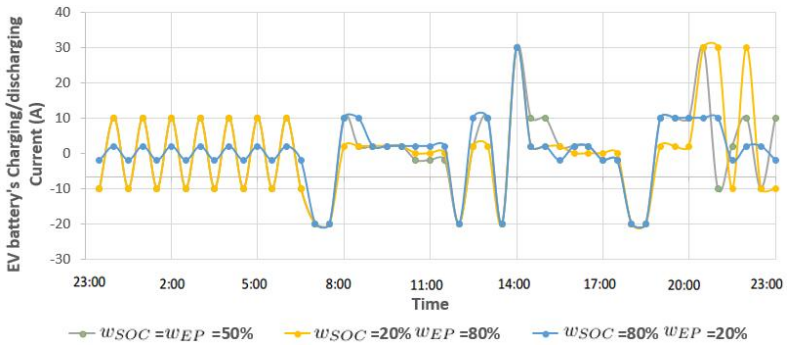

Figure 15. Charging/discharging currents of an EV battery under different settings of $w_{S O C}$ and $w_{E P}$ but constant $w_{G}(20 \%)$ and $w_{E V}(80 \%)$

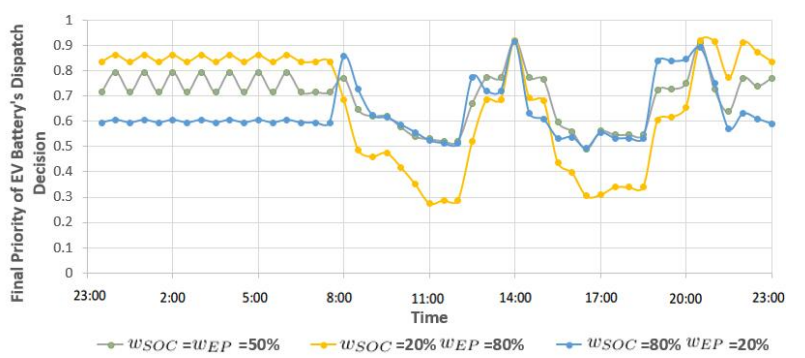

Figure 16. Final priorities of dispatch decisions of an EV battery under different settings of $w_{S O C}$ and $w_{E P}$ but constant $w_{G}(20 \%)$ and $w_{E V}$ (80\%), which decide the dispatch current levels in Figure 15 and hence SOC conditions in Figure 14

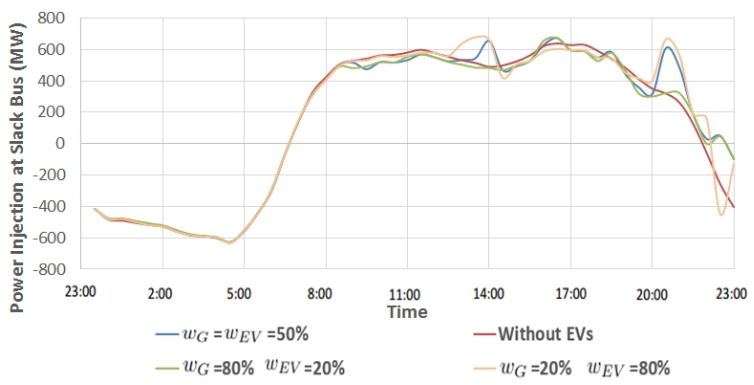

Figure 17. Daily power injections at the slack bus under different settings of $w_{G}$ and $w_{E V}$

TABLE VII

ACCUMULATED ENERGY INJECTIONS AT THE SLACK BUS UNDER DIFFERENT SETTINGS OF $w_{G}$ AND $w_{E V}$ IN 24 HOUR PERIOD

\begin{tabular}{|c|c|c|}
\hline$w_{G}$ & $w_{E V}$ & $\begin{array}{c}\text { Accumulated Energy in 24 hour period } \\
(\mathrm{MWh})\end{array}$ \\
\hline $20 \%$ & $80 \%$ & 3878.99 \\
\hline $50 \%$ & $50 \%$ & 3795.71 \\
\hline $80 \%$ & $20 \%$ & 3426.39 \\
\hline
\end{tabular}

the operation stage to produce sensible results. This may require some negotiations between the parties involved who may accept a compromise once they are informed about the implications of their choices and perhaps after their fears are allayed. Indeed the weighting of the factors and even the factors themselves may need to be changed with time as the system evolves.

Furthermore, the impact of increasing the percentage of V2G-enabled EVs on load levelling is illustrated in Figure 18 and 19. Figure 18 shows the power injected at the slack bus during a 24-hour period. As the percentage of V2G- enabled EVs increases, the peak shaving increases. In Figure 19 , the total accumulated energy injected into the slack bus during a 24-hour period is plotted against the percentage of V2G-enabled EVs. This graph was obtained by repeating the simulation 40 times for each percentage of V2G-enabled EVs; each simulation starts with a randomly assigned travel pattern; the mean and standard deviation of injected energy at the slack bus during a 24-hour period are calculated for each percentage of V2G-enabled EVs from the results of the 40 simulations. The accumulated energy injection reduces when more EVs participate in the V2G operation. That is just as expected and can be easily understood; increasing the percentage of V2Genabled EVs raises the available battery capacity that can be used to meet the power system demand.

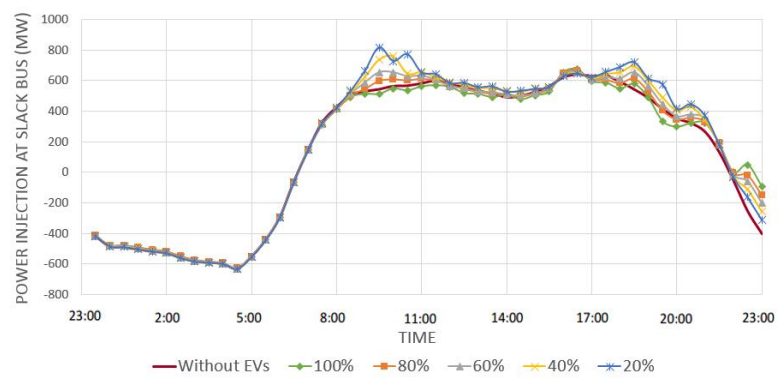

Figure 18. Power injections at the slack bus under different percentage of V2G-enabled EVs

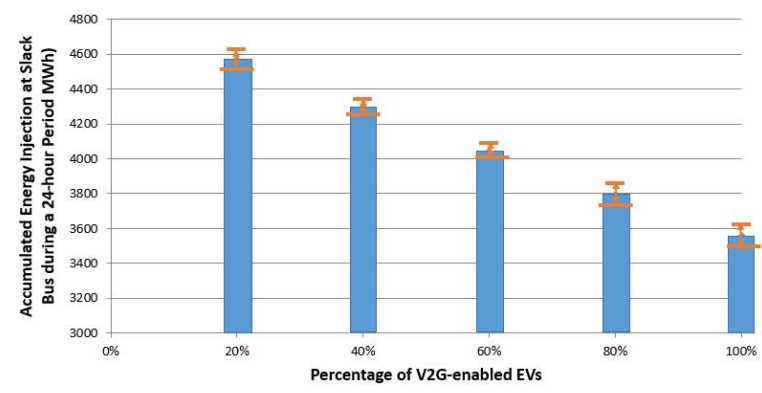

Figure 19. Average accumulated energy injections at the slack bus under different percentage of V2G-enabled EVs (Error bars represent \pm standard deviation)

It is important to note that this work presents the proposed AHP-based dispatch strategy using an example setting of the criteria weightings in the AHP hierarchy model and the percentage of V2G batteries. However, the settings of weightings can be adjusted by the EV aggregator (EVA) to accommodate its requirements and the actual situation of the network and EV cluster. The proportion of $\mathrm{V} 2 \mathrm{G}$ batteries in practice depends on the EV users' willingness and/or EV chargers' hardware.

Moreover, an estimate about the EV user's next journey is necessary for the proposed technique to carry out effective and customized dispatch. This information is expected to be supplied to the aggregator either when the vehicle is plugged into the charging point or through the internet. This does not need to be a burden to the EV user. For example, users could have an App (a software agent) supplied by the aggregator installed on their smart phones or computers that estimates the energy required for the next journey based on information 
in their calendar about their future activities (and the time and distance of the next journey), traffic conditions, weather, etc. They can send the energy requirement information (could be simply minimum SOC) to the aggregator automatically through the internet or wireless communication channels, without revealing any of their activities and without impacting their privacy. Forecasting tools can also be employed, based on historical records of the EV's previous driving activities, to provide a forecast of EV user's travel pattern including an estimate of the next journey's energy usage. Further research is needed on how this may be implemented in practice.

Furthermore, the AHP-based dispatch strategy is proposed for practical application, therefore the computational efficiency is an important factor. It takes only $0.3 \mathrm{~s}$ on average to make dispatch decisions for the total EV fleet of $625000 \mathrm{EVs}$ at each time step if using a computer with a Quad Core 3.4GHz CPU and 16GB RAM as an example, which provides an insight into the computation time required by the proposed algorithm.

Some information is needed to implement the proposed dispatch strategy, apart from the EV user's driving activities, such as the real-time pricing, network's load demand and $\mathrm{N}$ 1 contingency information. These are supposed to be notified a short while ahead of the beginning of every time interval, via wireless communication for example. However, if the communication is suspended due to a sudden accident, e.g. hacker attack, and some or all of the required information for the next time interval cannot be obtained in time, then an estimate or a forecast of the missing information will be used to dispatch the EVs. In more detail, if the exact pricing data is unknown, the aggregator can either use the available day-ahead electricity price or use forecasting tools, which can be embedded into the proposed model, to predict the price for the next time interval. The uncertain load demand for the next time interval can be dealt with in a similar way, that is, the day-ahead network load demand forecast can be used to implement the proposed dispatch strategy. Besides, if $\mathrm{N}-1$ contingency occurs without being able to inform the aggregator, then EVs will be dispatched as if no contingency occurred. Due to the inherent redundancy of $V 2 G$ and other energy storage that are in communication, this may not have a large impact as other EV clusters or stationary energy storage systems can participate in the alleviation of overload caused by the N-1 contingency. Note that it will be better to use exact real-time data in order for the proposed strategy to provide an accurate dispatch of EVs, however using well-estimated data for a certain time interval (when the communication breaks off) will not affect the dispatch decision of the proposed AHPbased strategy due to its robustness and inherent tolerance of uncertainty. One could envisage that the AHP priority factors may be adjusted depending on the level of confidence in the information, which in turn depends on whether they were based on actual information or estimated one, which could add further robustness. This matter deserves further investigation in the future.

\section{CONCLUSIONS}

This paper has proposed a novel decentralized dispatch strategy for the V2G batteries using the AHP methodology taking into account the requirements of both EV users and the grid, such that the EV batteries can be dispatched to save cost while ensuring reliable driving experience with sufficient SOC left in the battery and help to support the grid for load levelling or under N-1 contingency. The proposed dispatch strategy was tested on an IEEE Reliability Test System. The simulation results demonstrated the feasibility and efficacy of the proposed AHP-based dispatch strategy in satisfying the requirements of both EV users and the grid. Moreover, this strategy has proved to be generally better than the rulebased one proposed in [22]. Compared to the rule-based dispatch approach, it costs $£ 0.86$ more a day, per vehicle, but it improves the EV battery's SOC condition and performs better in terms of load levelling. Under the severe $\mathrm{N}-1$ contingency that overloads the branch close to the bus to which the EV is connected, the AHP-based dispatch strategy correctly selects the dispatch action of the EV battery that can help to alleviate the overloading.

In the application of $\mathrm{V} 2 \mathrm{G}$ batteries using the proposed AHP-based dispatch strategy, the EV aggregator gathers the real-time data a short while (e.g. 5 minutes) prior to the beginning of each time interval, as discussed earlier. Realtime pricing (RTP) data need to be downloaded from the electricity market on a half-hourly basis (i.e. before the start of every time interval of 30 minutes). RTP can be affected by the real-time demand and supply conditions, which include the dispatch of $\mathrm{V} 2 \mathrm{G}$ batteries, i.e. the charging as a load or discharging as a source. Moreover, as the electricity price is considered in the V2G battery dispatch, RTP will have impact on the determination of battery dispatch actions. Hence, there is interactive effect between V2G battery dispatch and RTP, which will be investigated in the future. Furthermore, the proposed AHP-based dispatch strategy is actually utilized by the $\mathrm{V} 2 \mathrm{G}$ aggregators, not by the EV users, as discussed earlier. In order to encourage the $\mathrm{V} 2 \mathrm{G}$ operation, incentive payments will be given to the EV users if they agree to let their vehicles participate in the grid operational support when needed. The settings of incentive payments and the relevant policy requires further investigations.

\section{REFERENCES}

[1] Z. Li, Q. Guo, H. Sun, Y. Wang, and S. Xin, "Emission-concerned windev coordination on the transmission grid side with network constraints: Concept and case study," IEEE Transactions on Smart Grid, vol. 4, no. 3, pp. 1692-1704, Sept 2013.

[2] A. Foley, B. Tyther, P. Calnan, and B. O. Gallachoir, "Impacts of electric vehicle charging under electricity market operations," Applied Energy, vol. 101, no. 0, pp. 93 - 102, 2013.

[3] F. Millo, L. Rolando, R. Fuso, and F. Mallamo, "Real CO2 emissions benefits and end user's operating costs of a plug-in hybrid electric vehicle," Applied Energy, vol. 114, no. 0, pp. 563 - 571, 2014.

[4] “Global EV market forecast," [Online], Dec 2012, Available: http://www. greencarcongress.com/2012/12/anderman-20121218.html.

[5] S. Gao, K. Chau, C. Liu, D. Wu, and C. Chan, "Integrated energy management of plug-in electric vehicles in power grid with renewables," IEEE Transactions on Vehicular Technology, vol. 63, no. 7, pp. 30193027, Sept 2014.

[6] C.-T. Li, C. Ahn, H. Peng, and J. Sun, "Synergistic control of plug-in vehicle charging and wind power scheduling," IEEE Transactions on Power Systems, vol. 28, no. 2, pp. 1113-1121, May 2013. 
[7] D. Dallinger, S. Gerda, and M. Wietschel, "Integration of intermittent renewable power supply using grid-connected vehicles - a 2030 case study for california and germany," Applied Energy, vol. 104, no. 0, pp. $666-682,2013$.

[8] J. Lopes, F. Soares, and P. Almeida, "Integration of electric vehicles in the electric power system," Proceedings of the IEEE, vol. 99, no. 1, pp. 168-183, Jan 2011.

[9] Y. Han, P. Young, A. Jain, and D. Zimmerle, "Robust control for microgrid frequency deviation reduction with attached storage system," IEEE Transactions on Smart Grid, vol. 6, no. 2, pp. 557-565, March 2015.

[10] S. Chen, T. Zhang, H. Gooi, R. Masiello, and W. Katzenstein, "Penetration rate and effectiveness studies of aggregated bess for frequency regulation," IEEE Transactions on Smart Grid, vol. PP, no. 99, pp. 1-1, 2015.

[11] S.-J. Lee, J.-H. Kim, C.-H. Kim, S.-K. Kim, E.-S. Kim, D.-U. Kim, K. Mehmood, and S. Khan, "Coordinated control algorithm for distributed battery energy storage systems for mitigating voltage and frequency deviations," IEEE Transactions on Smart Grid, vol. PP, no. 99, pp. $1-1,2015$

[12] Y. Wen, C. Guo, and S. Dong, "Coordinated control of distributed and bulk energy storage for alleviation of post-contingency overloads," Energies, vol. 7, no. 3, pp. 1599-1620, 2014.

[13] A. Del Rosso and S. Eckroad, "Energy storage for relief of transmission congestion," IEEE Transactions on Smart Grid, vol. 5, no. 2, pp. 1138 1146, March 2014.

[14] E. B. Iversen, J. M. Morales, and H. Madsen, "Optimal charging of an electric vehicle using a markov decision process," Applied Energy, vol. 123, no. 0, pp. $1-12,2014$.

[15] P. Richardson, D. Flynn, and A. Keane, "Optimal charging of electric vehicles in low-voltage distribution systems," IEEE Transactions on Power Systems, vol. 27, no. 1, pp. 268-279, Feb 2012.

[16] M. Singh, P. Kumar, and I. Kar, "Implementation of vehicle to grid infrastructure using fuzzy logic controller," IEEE Transactions on Smart Grid, vol. 3, no. 1, pp. 565-577, March 2012.

[17] L. Yang, J. Zhang, and H. Poor, "Risk-aware day-ahead scheduling and real-time dispatch for electric vehicle charging," IEEE Transactions on Smart Grid, vol. 5, no. 2, pp. 693-702, March 2014.

[18] T. Zhang, W. Chen, Z. Han, and Z. Cao, "Charging scheduling of electric vehicles with local renewable energy under uncertain electric vehicle arrival and grid power price," IEEE Transactions on Vehicular Technology, vol. 63, no. 6, pp. 2600-2612, July 2014.

[19] M. Yazdani-Damavandi, M. Moghaddam, M.-R. Haghifam, M. Shafiekhah, and J. Catalao, "Modeling operational behavior of plug-in electric vehicles' parking lot in multienergy systems," IEEE Transactions on Smart Grid, vol. PP, no. 99, pp. 1-1, 2015.

[20] O. Erdinc, N. Paterakis, T. Mendes, A. Bakirtzis, and J. Catalao, "Smart household operation considering bi-directional ev and ess utilization by real-time pricing-based dr," IEEE Transactions on Smart Grid, vol. 6, no. 3, pp. 1281-1291, May 2015.

[21] L. Hua, J. Wang, and C. Zhou, "Adaptive electric vehicle charging coordination on distribution network," IEEE Transactions on Smart Grid, vol. 5, no. 6, pp. 2666-2675, Nov 2014.

[22] Y. Ma, T. Houghton, A. Cruden, and D. Infield, "Modeling the benefits of vehicle-to-grid technology to a power system," IEEE Transactions on Power Systems, vol. 27, no. 2, pp. 1012-1020, May 2012.

[23] T. L. Saaty, The Analytic Hierarchy Process. New York: McGraw Hill, 1980.

[24] D.-M. Kim and J.-O. Kim, "Design of emergency demand response program using analytic hierarchy process," IEEE Transactions on Smart Grid, vol. 3, no. 2, pp. 635-644, June 2012.

[25] J. Zhu and M. Irving, "Combined active and reactive dispatch with multiple objectives using an analytic hierarchical process," IEE ProceedingsGeneration, Transmission and Distribution, vol. 143, no. 4, pp. 344-352, Jul 1996.

[26] J. Zhu and J. A. Momoh, "Optimal VAr pricing and VAr placement using analytic hierarchical process," Electric Power Systems Research, vol. 48 , no. 1 , pp. $11-17,1998$.

[27] J. Larminie and J. Lowry, Electric Vehicle Technology Explained. England: John Wiley \& Sons, 2003.

[28] D. Doerffel and S. M. Sharkh, "A critical review of using the peukert equation for determining the remaining capacity of lead-acid and lithium-ion batteries," Journal of Power Sources, vol. 155, no. 2, pp. $395-400,2006$.

[29] S. Han, S. Han, and H. Aki, "A practical battery wear model for electric vehicle charging applications," Applied Energy, vol. 113, pp. $1100-$ $1108,2014$.
[30] SAFT, "Lithium-ion battery life," [Online], Available: http://www.saftbatteries.com/force_download/li_ion_battery_life_ TechnicalSheet_en_0514_Protected.pdf.

[31] "UK national grid," [Online], Jan 2014, Available: http://www. bmreports.com/bwx_reporting.htm.

[32] P. M. Subcommittee, "IEEE reliability test system," IEEE Transactions on Power Apparatus and Systems, vol. PAS-98, no. 6, pp. 2047-2054, Nov 1979.

[33] R. D. Zimmerman, C. E. Murillo-Sanchez, and R. J. Thomas, "Matpower: Steady-state operations, planning and analysis tools for power systems research and education," IEEE Transactions on Power Systems, vol. 26, no. 1, pp. 12-19, Feb 2011.

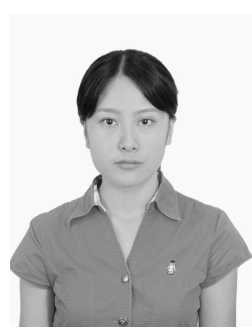

Lu Wang obtained her BEng degrees in Electrical and Electronic Engineering from the University of Birmingham and Huazhong University of Science and Technology in 2013. She is currently pursuing the $\mathrm{PhD}$ degree in the Faculty of Engineering and the Environment at the University of Southampton.

Her research interest includes optimization and control of smart grid, vehicle-to-grid, energy storage and renewable energy integration.

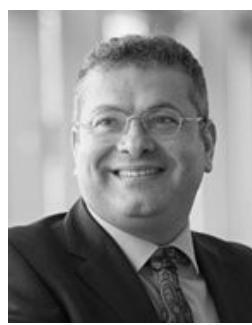

Suleiman Sharkh obtained his BEng and $\mathrm{PhD}$ degrees in Electrical Engineering from the University of Southampton in 1990 and 1994, respectively. $\mathrm{He}$ is currently the Head of the Electro-Mechanical Engineering Research Group at the University of Southampton and Professor of Power Electronics, Machines and Drives.

His research interests include high performance electrical machines and power electronics for demanding applications.

Prof. Suleiman Sharkh was the winner of The Faraday SPARKS Award in 2002 and The Engineer Energy Innovation and Technology Award in 2008.

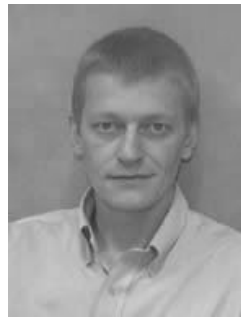

Andy Chipperfield graduated with a BSc(Hons) in Computer Systems Engineering from University College of North Wales, Bangor, in 1989. In 1995 he obtained his $\mathrm{PhD}$ on computer aided control systems design from the Department of Automatic Control and Systems at the University of Sheffield as a research assistant.

In 2002 he joined Southampton as a senior lecturer in computational methods. His current research is primarily focused on applying these systems engineering techniques to problems in biomedical and

clinical science.

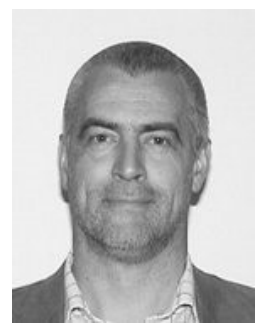

Andrew Cruden obtained his BEng, MSc and $\mathrm{PhD}$ degrees in Electronic and Electrical Engineering from the University of Strathclyde, Glasgow, in 1989, 1990 and 1998, respectively. He is currently the Head of the Energy Technologies Research Group at the University of Southampton and Professor of Energy Technologies.

He has significant experience in the field of renewable energy, particularly in fuel cell technology and condition monitoring of wind turbines. The interest in fuel cell technology led, indirectly, to an interest in the field of electric vehicles, and subsequently to research activity in energy storage and traction drives. 